\title{
Next generation geoenvironmental deposit models - promoting sustainable utilisation of layered intrusions
}

\author{
T. Kauppila \\ Geological Survey of Finland, PO Box 1237, 70211 Kuopio, Finland \\ E-mail: tommi.kauppila@gtk.fi
}

\begin{abstract}
Summary Geoenvironmental mineral deposit models are based on the observation that different deposit types result in type-specific environmental impacts when mined. It is possible to predict the most likely mining and processing methods and, therefore, environmental impacts caused by each deposit type. This approach can be taken one step further by also considering the deposit location as this also affects both the environmental impacts and the regional opportunities of mining a certain type of deposit. Such a profiling can be carried out using publicly available spatial data sets. This presents possibilities also for layered intrusions research as models like this can be used to compare exploration targets for project portfolio and risk management, investment decisions, and transparent communication of exploration for the public.
\end{abstract}

\section{Introduction}

The demand for primary mineral resources by societies is in the increase globally. This change is driven by the increase in population and, importantly, the general standard of living in all parts of the world. In addition, an unprecedented shift in the demand for certain primary mineral-based raw materials is driven by the recent shift to green technologies in especially energy production and storage and in electric mobility (e.g., Xu et al. 2020). The latter shift in particular is based on sustainability and environmental arguments and promise. This requirement naturally extends also upstream in the value chain and the production of primary raw materials also needs to live up to the sustainability promise.

For primary mineral production to be sustainable, certain requirements need to be met (Kauppila, 2018). We will need to seek measures that promote a viable mining industry capable of solid environmental management investment. We will also need to maintain a high exploration activity to produce data, methods, and prospects to replace the deposits that we are mining for the benefit of the current generation. At all time, losses of natural capital other than the exhaustion of the deposit should be minimized in mining operations while local sustainable benefits are maximized.

All of these important facets of sustainability of mining projects are linked to one another and also to the public acceptance for mining projects, often called social license to operate. Public acceptance is crucial for high exploration activity and environmental issues are in the core of acceptance issues. Therefore, we need better tools to predict, mitigate, and communicate the risks of exploration and mining projects and to communicate all this to the public in an open and trustworthy manner.

Exploration projects typically lack public acceptance not because of the impacts of exploration as such but because of the anticipated impacts of the mining operation that might arise from successful exploration. This is the case even if most exploration projects never produce results that warrant a mine. Tools are therefore needed to systematically and transparently analyse the risks and opportunities related to exploration targets and to communicate the findings to the public. In addition, the industry needs tools to efficiently 
compare the properties of exploration targets for investment decisions, project portfolio management, and risk management.

Geoenvironmental mineral deposit models are tools that seek to extend the ore deposit models to also predict the environmental pressures caused by the most likely mining operations that might be used to mine the deposit at hand (e.g., Seal \& Foley, 2002). Such models could be used to analyze exploration projects at an early stage, provided that some predictions of the target deposit types (e.g. layered intrusions) are available. In addition, spatial data sets are increasingly available that could be used to also take into account the location-specific properties of the exploration area. These properties have a bearing on the vulnerability of the site surroundings for mining impacts and on the regional benefits that might be gained from a mining project. Such spatial data-based models can be termed next generation geoenvironmental deposit models as they take the approach further from the static, report-like format. This paper examines the possibilities of and approaches for next generation geoenvironmental mineral deposit models and the opportunities they provide for exploration targeting layered intrusions.

\section{Research questions}

Next generation geoenvironmental mineral deposit models are based on three assumptions: 1) deposit properties affect the properties of the mining operation and, therefore, the environmental impacts, 2) deposit location affects how vulnerable the site and its surroundings are to the mining-related stressors and how the region can benefit from the project, and 3) modern publicly available data sets can be used to analyze both of the points above to produce useful analyses that describe the components of risk and opportunities of the exploration targets.

\subsection{Deposit properties affect environmental management challenges}

Original geoenvironmental deposit models, and the modern ones as well, are based on the observation that deposit types affect the environmental management challenges encountered. Some mines are much easier to run with minimal environmental effects than others. The most common divisions are between metal mines and non-metal mines and between sulfidic and oxide metal mines. However, the issue is much more complex and requires that the properties of the country rock also is considered. This issue as well as things such as deposit geometry highlight the need for a model that is scalable. The model should be able to take into account data on deposit properties as it becomes available during exploration and the predictions should be updated accordingly. It is of great importance that the authorities are able to take the uniqueness of each deposit into account in making decisions on licensing and environmental permitting and models such as these can support authorities in facts-based decision making.

\subsection{The effect of deposit manifests through process options and waste properties}

The effects deposit properties have on the expected impacts of a mining operation are mainly based on two mechanisms: the properties of mining wastes (waste rock and tailings) and the methods selected to mine and process the ore. Current deposit models can be analysed and improved to provide reasonable estimates of also waste rock properties and useful predictions of tailings properties are also possible even though all deposits are unique in properties. For both waste types, predictions need to consider properties that are relevant for waste management, a feature not common in current deposit models.

A crucial feature in classical and modern geoenvironmental deposit models is the ability to predict the most likely mining and processing methods for the deposit types. This is, indeed, achievable with current expertise and with support from analysing current projects for similar deposits, if available. Scalability is of importance here and predictions should be updated as 
more information on the deposit is collected. Deposit properties affect not only the mining and processing methods but also the amounts of waste, types of emissions, hazards present, and the timing and duration of the expected impacts. Importantly, modern geoenvironmental models need to also take hazard and impact management measures into account. For instance, mining wastes should no longer only be seen as environmental hazards but also opportunities for beneficial uses such as backfilling. Similarly, the models should be able to handle brownfields sites as these are becoming increasingly common.

\subsection{Deposit location affects framework conditions, risks and benefits}

Because of the way classical geoenvironmental deposit models have been designed and presented, they typically do not take the environmental setting (location) of the exploration area or deposit into account. However, locations have a profound impact on both the environmental impacts of a project and the opportunities to generate sustainable benefits from mining. Not all deposit types produce similar impacts and some locations are riskier than others. Location also dictates many framework conditions for exploration and mining, such as protected areas, land ownership, or competing land uses.

Several features of the environment can have an effect on the impacts of mining-related emissions and other stressors at the site. Things such as topography, climate, hydrology, surface water bodies, surficial geology (e.g. aquifers), vegetation, other biota, rare and endangered species, specific habitats, background concentrations etc. all affect environmental risks. Similarly, factors such as human settlement, farming, fishing, sources of drinking water, other human food chain properties, and other exposure factors affect risks to human health. Properties of the surrounding society, in turn, have an effect on how sustainable benefits can be generated from the mining project.

\subsection{Data sets and analysis methods}

Next generation geoenvironmental deposit models not only utilize open spatial data sets to define the properties of the location surrounding the deposit but also information on the deposit types and mineral systems and modern methods of mining, processing, waste utilization, and environmental management. Current mineral systems thinking is at the core of the approach and allows extending the predictions to a larger area than deposit models alone. Modern deposit models, in turn, not only make predictions of deposit properties more accurate, but can be expanded to take environmental management-relevant properties of both the ore and its host rocks into account.

The next step in the analysis is then the unit process options available for each deposit type. These can extend upstream to the exploration phase and include mining methods, on-site mineral processing options, waste utilization and management, environmental management and emission abatement options, continuous progressive closure, final closure, and post closure land uses. Some of these processes are ones that generate emissions or pressures on the environment while others are used to reduce these emissions. The net result is thus a combination of the adopted process options.

With the deposit and project properties determined, the next step is profiling of the site with respect to vulnerability, impacts, and opportunities. This is based on spatial data sets that preferably are publicly available. The analysis targets ecological risks, health risks, spreading of contaminants, social impacts and opportunities, regional economic impacts, and framework conditions for exploration and mining. Each component of the analysis requires specific expertise on the question at hand and the final product must be a combination of all these various branches of assessment. 


\subsection{Profiling rather than scoring}

For all steps and components listed above (deposit and mineral system properties, unit processes at an operating mine, and impacts and opportunities assessment), the aim is not to provide a deterministic scoring. Rather, the aim is to analyse and make visible the characteristics of each component that together describe the most likely operation that might be based on a certain deposit and the resulting impacts in that specific location. Therefore, the model provides a description, with ranges of uncertainty, of each component separately to produce an impact profiling of the exploration target. It can also offer the users the possibility to weight the components according to their specific needs. Furthermore, the system should be compatible with classifications such as the UNFC to be as useful as possible.

\section{Opportunities for layered intrusions}

To date, spatial data-based next generation geoenvironmental mineral deposit models capable of profiling and comparing exploration targets do not exist. However, the expertise to construct such systems is available for all the individual components required. As tools like this will promote acceptable exploration, exploration portfolio management, investment decisions, and risk management, there is an incentive for researchers in layered intrusions to promote their deposit types by developing the deposit and mineral systems part of such models. This may prove to be a competitive advantage in the future with a widespread adoption of such models in exploration management.

\section{References:}

Kauppila, T. 2018. Mining non-renewable mineral resources in a sustainable way. European Geologist 45: 11-14. Seal, R.R. III \& Foley, N.K. 2002. Progress on Geoenvironmental Models for Selected Mineral Deposit Types. Publications of the US Geological Survey. Paper 83. $218 \mathrm{p}$.

Xu, C., Dai, Q., Gaines, L., Hu, M., Tukker, A. \& Steubing, B. 2020. Future material demand for automotive lithium-based batteries. Communications Materials 2020:199 